\title{
Cardiac Surgery 2019 Reviewed
}

\author{
Torsten Doenst ${ }^{1}$ Steffen Bargenda ${ }^{1}$ Hristo Kirov ${ }^{1}$ Alexandros Moschovas ${ }^{1}$ Sophie Tkebuchava ${ }^{1}$ \\ Rauf Safarov $^{1}$ Ilia Velichkov ${ }^{1}$ Mahmoud Diab ${ }^{1}$ \\ ${ }^{1}$ Department of Cardiothoracic Surgery, Friedrich-Schiller University \\ of Jena, Jena, Germany \\ Address for correspondence Torsten Doenst, MD, PhD, Department \\ of Cardiothoracic Surgery, Friedrich-Schiller University of Jena, Am \\ Klinikum 1, 07747 Jena, Germany (e-mail: doenst@med.uni-jena.de).
}

Thorac Cardiovasc Surg 2020;68:363-376.

\begin{abstract}
Keywords

- coronary revascularization

- aortic valve surgery

- mitral valve surgery

- tricuspid valve surgery

- left ventricular assist device

- heart transplantation

For the year 2019, almost 25,000 published references can be found in PubMed when entering the search term "cardiac surgery." We used the Preferred Reporting Items for Systematic Reviews and Meta-Analyses approach for article selection and reviewed the main fields of adult cardiac surgery (i.e., coronary, valve, aortic, and heart failure surgery). The past decade has experienced an enormous development of interventional techniques that compete more and more with classic surgery. This contest was broadly visible in 2019. It peaked over the interpretation of the EXCEL trial data, where percutaneous coronary intervention and coronary artery bypass grafting (CABG) for left main disease were compared. A novel pathomechanism for CABG was proposed, potentially answering open questions in the field. In aortic valve surgery, two low-risk trials comparing transcatheter aortic valve implantation (TAVI) to classic aortic valve replacement (surgical aortic valve replacement) received attention for showing equal or superior short-term outcomes for TAVI. Longer follow-up information from recent trials became available presenting results emphasizing the need for joint decision making. While publications addressing surgery on the aorta and the mitral and tricuspid valves were less abundant, there was substantial activity regarding left ventricular assist device support and heart transplantation. This article attempts to summarize the most pertinent publications. It does not expect to be complete and cannot be free of individual interpretation. We aimed to provide a condensed summary of 2019 s publications with a stimulus for in-depth reading and a basis supporting patient information.
\end{abstract}

\section{Introduction}

We used the Preferred Reporting Items for Systematic Reviews and Meta-Analyses (PRISMA) approach for a systematic literature review. The MEDLINE database was searched using the following search terms combined with the publication date being between January 1, 2019, and December 31, 2019, for the different sections of this article: Coronary Artery Bypass Grafting; Aortic Valve; TAVI; Aortic Valve Disease; Mitral Valve Surgery; MitraClip; Tricuspid Valve; Aortic Aneurysm; Aortic dissection; LVAD; Mechanical Circulatory Support and Heart Transplantation; clinical trial. -Supplementary Fig. S1 (online only) shows the Preferred Reporting Items for System-

received

March 12, 2020

accepted after revision

May 18,2020

published online

June 27, 2020

atic Reviews and Meta-Analyses diagram for the literature review. We selected publications based on their value for indications, decision making, and patient information. Articles with focus on individual technical details without relevant information for the above-described goals were omitted.

\section{Surgical Treatment of Coronary Artery Disease}

In 2019, publications in the field can be separated into four categories: (1) studies addressing coronary artery bypass grafting (CABG) versus percutaneous coronary intervention (PCI), (2) new diagnostic tools for diagnosis and treatment of (c) 2020 Georg Thieme Verlag KG
Stuttgart · New York
DOI https://doi.org/ 10.1055/s-0040-1713648. ISSN 0171-6425. 
coronary artery disease (CAD), (3) technical aspects of CABG conduct, and (4) the role of medical therapy in CABG patients.

\section{CABG versus $\mathrm{PCI}$}

Recent years have been filled with publications addressing comparisons of CABG and PCI. Two years ago, a large patientlevel meta-analysis of the most pertinent randomized trials demonstrated a survival advantage for CABG compared with $\mathrm{PCI}$ in multivessel disease. This CABG survival advantage can be observed repeatedly in various trials and registry analyses and seems to be dependent on the severity of CAD. ${ }^{1}$ This recognition is also reflected in the 2018 revised guidelines for myocardial revascularization. ${ }^{2}$

In 2019, we published an investigation exploring the mechanisms through which PCI and CABG mediate their treatment effect. ${ }^{3}$ - Fig. 1A shows autopsy examinations of coronary artery trees relating the degree of coronary artery stenosis to its likelihood to occlude a vessel ( - Fig. 1A, I) or to cause an infarction ( - Fig. 1A, II). The image gives rise to three important recognitions. First, the likelihood for vessel occlusion increases with the severity of coronary artery stenoses present. Second, there were more occlusions than infarctions caused, an observation supporting the well-known phenomenon of a clinically silent vessel occlusion, which is generally explained by the presence of collaterals. ${ }^{4}$ Third, the majority of myocardial infarctions are caused by nonflow limiting coronary artery stenoses ( $86 \%$ by stenosis less than $70 \%$ ). The last recognition gives rise to the question whether $\mathrm{PCI}$ (independent of stent type) can be expected to prevent new-onset myocardial infarction in a statistically relevant dimension. This question receives clinical support from repeated trials reporting no survival benefit and no impact of PCI on new myocardial infarctions in comparison to medical therapy (Stergiopoulos et $\mathrm{al}^{5}$ and see later). Our article also illustrates the inability of randomized studies to demonstrate that ischemia testing may predict outcome after myocardial revascularization (with either PCI or CABG, see later and the original article for more details). We were then able to show that the repeatedly demonstrated survival advantage of CABG compared with $\mathrm{PCI}$ was visible every time, and there was also a difference in the rate of new myocardial infarctions. Thus, it is our suggestion that coronary bypass surgery prolongs life not primarily by revascularization but first and foremost by surgical collateralization (i.e., by providing protection against new infarctions, -Fig. 1B). We thereby revive the concept that has been proposed already 10 years ago by Jeon et $\mathrm{al}^{6}$ who demonstrated that the insertion of a bypass graft is usually distal to the site of thrombotic vessel occlusion.

There were many publications in 2019 comparing PCI and CABG, which also present data suggestive of a link between mortality and new myocardial infarctions. A meta-analysis of 15 studies in more than 13,000 patients with a follow-up of up to 5 years demonstrated that CABG provides a lasting impact versus $\mathrm{PCI}$ in the occurrence of new myocardial infarctions during follow-up. ${ }^{7}$ This reduction in infarct occurrence was largest after 5 years and was not diminished by the use of drug-eluting stents.
The FREEDOM trial presented its 8-year outcomes with again a significant survival advantage of CABG over PCI in patients with double- and triple-vessel disease and diabetes mellitus. ${ }^{8}$ While this 8 -year follow-up of the original trial patients only recorded survival information, a single-center analysis on 430 freedom-like patients, who received either medical, interventional, or surgical therapy, demonstrated the lowest long-term mortality and the lowest rate of new myocardial infarctions in the CABG group. ${ }^{9}$

A meta-analysis of 20 studies comparing PCI and CABG in patients with reduced ejection fraction and at least 1 -year follow-up (more than 54,000 patients) demonstrated again a mortality benefit for $\mathrm{CABG}$ over $\mathrm{PCI}$, again associated with a reduction in new-onset myocardial infarctions. ${ }^{10}$

In the setting of non-ST segment elevation myocardial infarction (NSTEMI), an Israeli multicenter analysis on more than 5,000 patients, of which $15 \%$ were operated, demonstrated 447 risk-adjusted patient pairs that CABG provided a survival advantage associated with a reduction in new-onset myocardial infarctions. ${ }^{11}$ Another single-center analysis on 1,100 multivessel disease patients with NSTEMI also demonstrated a survival advantage for CABG. ${ }^{12}$ Although the authors did not present information on myocardial infarctions during follow-up, the survival impact was visible once the SYNTAX score exceeded 22.

Assuming that more complex CAD carries greater risk for new infarctions, this rationale is able to explain the 10-year results from the SYNTAX trial, ${ }^{13}$ where complete follow-up was generated by the participating centers without additional funding. The only end point that was monitored demonstrated a nonsignificant difference in survival at 10 years, but a very much significant survival advantage for CABG if the SYNTAX score was more than 32. Examining the survival curves demonstrates that after 5 years, the curves for PCI and CABG narrow again. One vague speculation may be that bypass graft occlusions over time (most grafts in SYNTAX were veins) may be responsible (infarct protection would get lost with graft occlusion).

Another group of patients with high risk for myocardial infarctions are patients with chronic kidney disease. A Veterans Affairs hospital registry analysis on almost 1,000 patients having received CABG or $\mathrm{PCI}$ in patients with chronic kidney disease who became dialysis dependent within the next 5 years again revealed a survival advantage for the CABG population (-Fig. 1C). ${ }^{14}$

Finally, the 5-year results of the EXCEL trial were presented. The trial compared $C A B G$ versus $\mathrm{PCI}$ in patients with left main CAD and a SYNTAX score less than $32 .{ }^{15}$ The primary outcome consisted of death myocardial infarction and stroke and was reported as not significantly different at 5 years ( - Fig. 1D). Since there had been previous discussions on the definition of myocardial infarction used by this trial ${ }^{16}$ and the fact that all-cause mortality at 5 years was significantly lower with CABG, a fierce discussion arose, resulting in one of the main surgeons of the trial withdrawing his authorship from the 5-year article. The discussion culminated in the European Association for Cardio-Thoracic Surgery (EACTS) withdrawing its support for the current European 
A

\section{I}

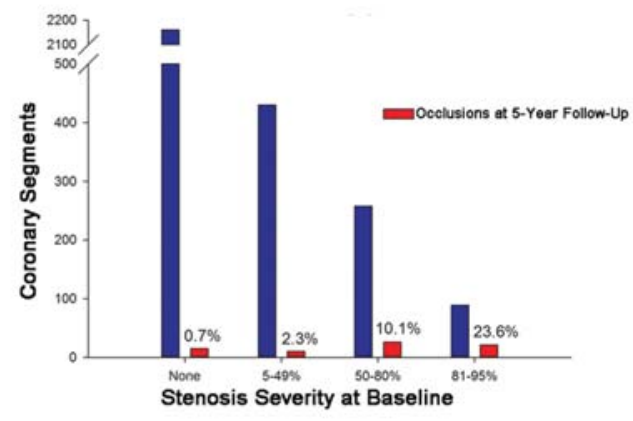

II

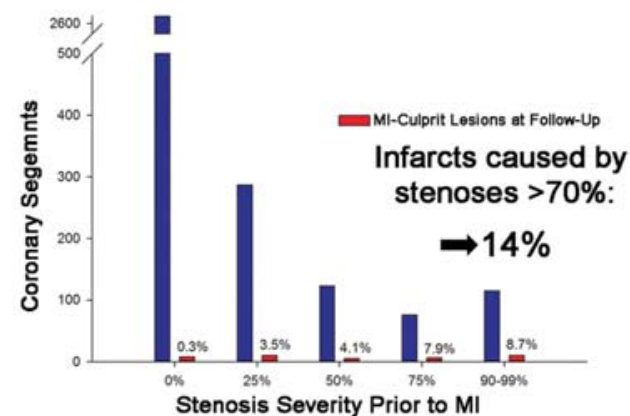

B

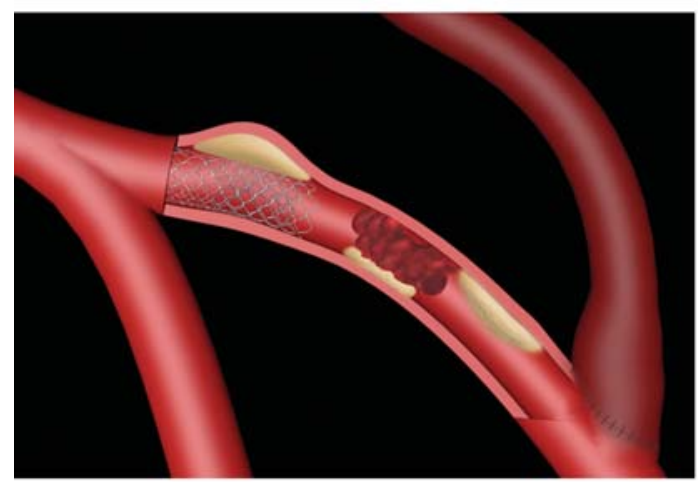

C

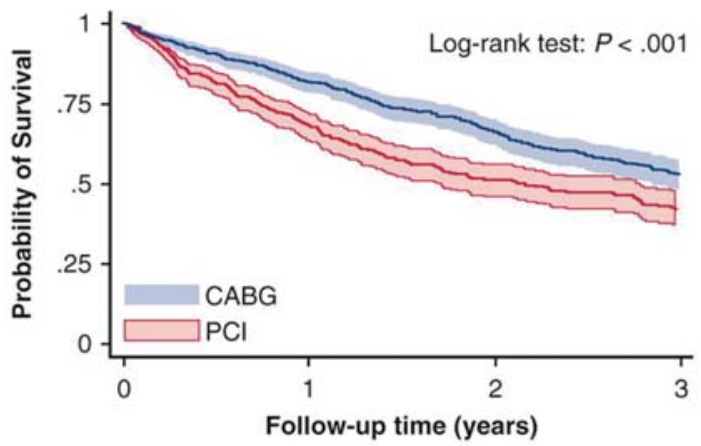

D

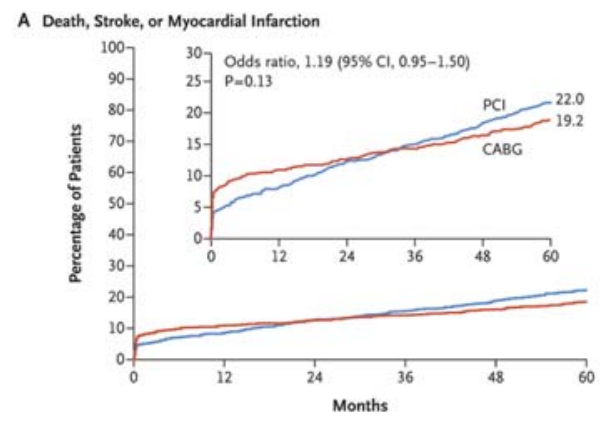

E

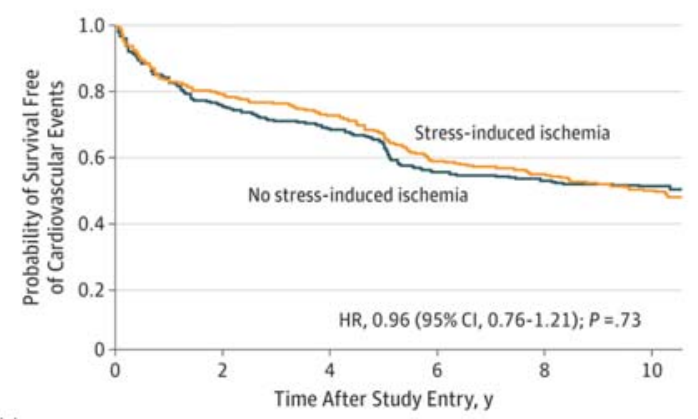

No. at risk
No stress-induced
ischemia
Stress-induced

ischemia

Fig. 1 Main findings of 2019 publications on invasive treatment of coronary artery disease. (A) Relationship between coronary artery stenosis severity in pathological vessel segments and vessel occlusion (I) or infarct occurrence (II). Relating the occurrence of infarction to vessel stenosis shows that vessels with more than $70 \%$ stenosis cause only $14 \%$ of all myocardial infarctions. (B) Schematic illustration how bypass grafting but not stenting can protect against infarction from not flow-relevant stenoses. (C) Kaplan-Meier's survival of patients with end-stage renal failure having received either CABG or PCI. ${ }^{14}$ (Reproduced with permission.) (D) Primary end point of the EXCEL trial at 5 years. ${ }^{15}$ (Reproduced with permission.) (E) Survival free of CV events in the MASS II patient population (including CAD patients with medical, $\mathrm{PCI}$, and/or $\mathrm{PCl}$ treatment) depending on the ability to induce ischemia by stress testing. ${ }^{20}$ (Reproduced with permission of CC-BY license.) CABG, coronary artery bypass grafting; CV, Cardiovascular; $\mathrm{PCl}$, percutaneous coronary intervention.

guidelines on myocardial revascularization. At the time of submission, the controversy was still unresolved. (Press release Prof. Pagano, Secretary General of the EACTS: https://www.eacts.org/eacts-responds-to-bbc-newsnights- investigation-on-the-excel-trial/, December 9, 2019). Irrespective of this discussion and of the definition for myocardial infarction used, the published data already contain information that supports the connection between death 
and new-onset myocardial infarctions. In the time from 30 days to 5 years, death rate was significantly higher in the PCI group (12.4 vs. 9.1\% in CABG) which was associated with a myocardial infarction rate that was almost twice as high as in the PCI group (6.8 vs. $3.5 \%$ in CABG). ${ }^{15}$ Finally, the NOBLE trial, assessing PCI and CABG for left main disease in a similar patient population as EXCEL demonstrated less myocardial infarctions with CABG at 5 years, although in this study, there was no difference in mortality between the groups. $^{17}$

The recognition, that a survival advantage may primarily be mediated by protection against new infarctions, may be sobering, but the notion is not new. ${ }^{5,18}$ To assess the impact of revascularization according to current guideline recommendations on outcome in patients with relevant CAD and evidence for ischemia, the ISCHEMIA trial was conducted. The trial compared a conservative, medically treated arm with an invasive treatment arm consisting of three quarters of PCI and one quarter of CABG patients. The final article has just been published. The primary end point (consisting of cardiovascular death, myocardial infarction, hospitalization for unexpected angina, heart failure, or survived resuscitated cardiac arrest) confirmed previous findings that the invasive strategy was not better than conservative therapy at 5 years (although curves crossed at 3 years) and that there was no difference at all in all-cause mortality over the 5 years.

A similar conclusion was drawn by the STICH trial 10-year results, in which all patients where viability testing was performed were assessed. The study concluded that knowledge of viability or nonviability did not affect the survival advantage provided by CABG, again questioning the role of revascularization as main mechanism for the survival advantage associated with CABG. ${ }^{19}$

Finally, a follow-up analysis of the MASS II trial, where patients were randomized between 1995 and 2000 to medical therapy $\mathrm{PCI}$ or $\mathrm{CABG}$, analyzed the role of ischemia detection by electrocardiogram stress testing (Bruce protocol). The authors found that the detection of ischemia did not predict the probability of survival free of cardiovascular events (- Fig. 1E). ${ }^{20}$

In summary, it appears reasonable to conclude from the data in 2019 alone that a prognostic impact of all current therapies for the treatment of stable CAD (now also termed chronic coronary syndromes) stems mainly from surgical collateralization and probably less so from revascularization. Thus, it may be time to rethink our terminology of our invasive treatment strategy (specifically for CABG) and to assess patients with chronic coronary syndromes not only by their number of severe coronary lesions but also by their risk to develop new myocardial infarctions.

\section{New Tools for the Diagnosis and Treatment of Coronary Artery Disease}

After the SYNTAX III Revolution trial demonstrated the feasibility to provide treatment recommendation for invasive therapy based on coronary computed tomography (CT) imaging in patients with triple-vessel disease, ${ }^{21}$ the same group demonstrated in 2019 that surgeons are able to plan CABG surgery based on the sole availability of CT coronary images in the majority of cases (80\%). ${ }^{22} \mathrm{~A}$ trial to test its practical feasibility is underway.

Another new diagnostic tool for the planning of CABG surgery is based on functional flow assessments over coronary stenoses such as the determination of the fractional flow reserve (FFR). The GRAFFITI trial randomized 172 patients in a group with classic assessment of bypass graft targets and one group where FFR assessment was used for graft selection. ${ }^{23}$ The classic group received on average one graft more than the FFR group (three vs. two grafts). Within the 12 months follow-up, there was no difference in adverse events, mortality, and importantly in patency rates ( - Fig. 2A). In contrast, the IMPAG trial assessed 199 coronary lesions in 67 patients by FFR measurement. ${ }^{24}$ They then performed fully arterial revascularization as judged by classic eyeball assessment. There was no mortality and no adverse events within the 6 months follow-up. Patency was controlled after 6 months with coronary CT and outcomes related to FFR values before surgery. The authors found that $96 \%$ of all grafts were classified as perfect if the FFR value was less than 0.79 . If the FFR value was more than 0.79 , the fraction of occluded grafts was up to $20 \%$ in the sequential setting and more than $50 \%$ in a single graft setting.

Considering our surgical collateralization hypothesis, the important information is that in both trials earlier, bypass grafting irrespective of FFR value did not increase adverse events. Graft occlusions were silent. Thus, even a 50\% chance of a graft remaining open may be considered an additional piece of protection against new infarctions. ${ }^{3}$

\section{Technical Aspects of CABG Conduct}

The issue of graft patency and its related morbidity moves center stage if it comes to technical aspects of CABG conduct. The controversy regarding off-pump's ability to provide similar precision, completeness of revascularization, and patency of grafts were fueled by several publications in 2019. A subanalysis of the EXCEL trial comparing on-pump to off-pump patients revealed inferior survival in the offpump patients. ${ }^{25}$ In contrast, a German analysis suggests that off-pump surgery may be superior to on-pump surgery in patients with previous coronary bypass surgery. ${ }^{26}$ Finally, the German GOPCABE trial compared off- and on-pumps in the elderly patients. The 5-year outcome showed no difference between groups but demonstrated that the long-term survival of the combined operative cohort was better than that of the age-matched German population (- Fig. 2B) ${ }^{27}$

A series of large registry studies then demonstrated in 2019 that fully arterial revascularization is associated with a survival benefit and increased patency rates. ${ }^{28-30}$ The 10 -year results of the ART trial may serve as perfect example illustrating the above-described controversy. The trial randomized more than 3,000 patients to the use of the left thoracic artery plus radial or vein grafts or the use of bilateral thoracic arteries plus vein or radial artery grafts. The intention-to-treat primary end point of death from any cause at 10 years demonstrated equal outcome (-Fig. 2C, I). The as-treated subanalysis of single arterial versus multiple arterial bypass grafting then demonstrated a significant survival advantage for multiple arterial grafts, suggesting 
A

I

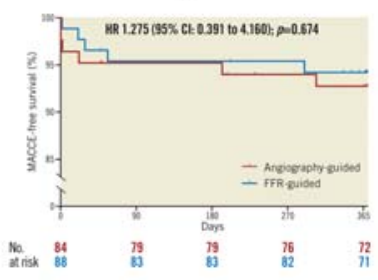

II

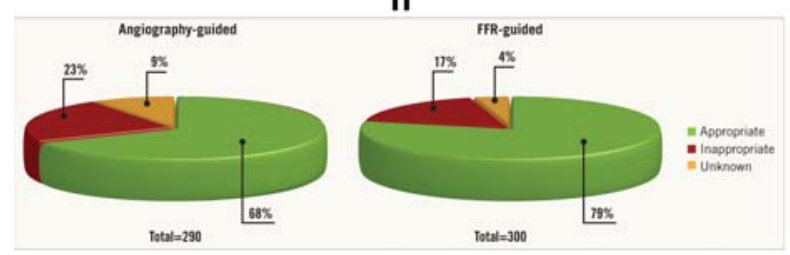

B

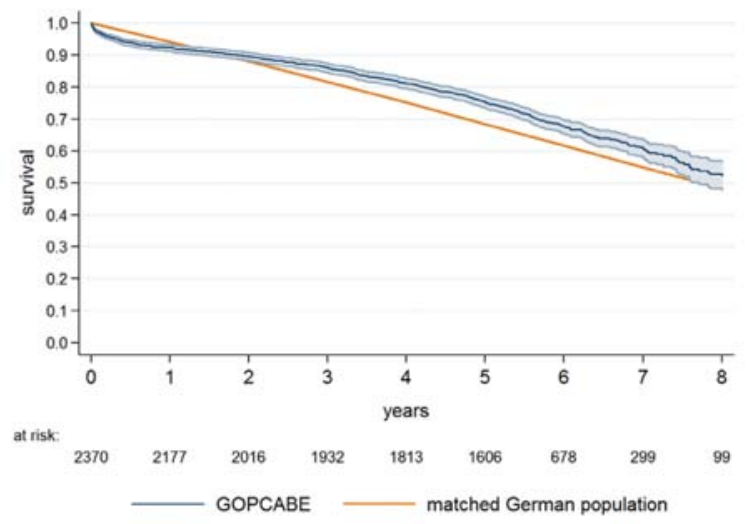

C

D

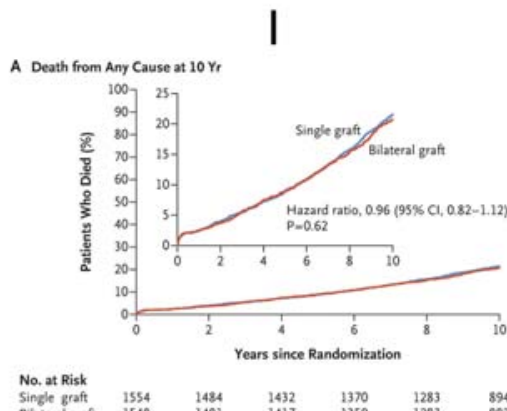

A
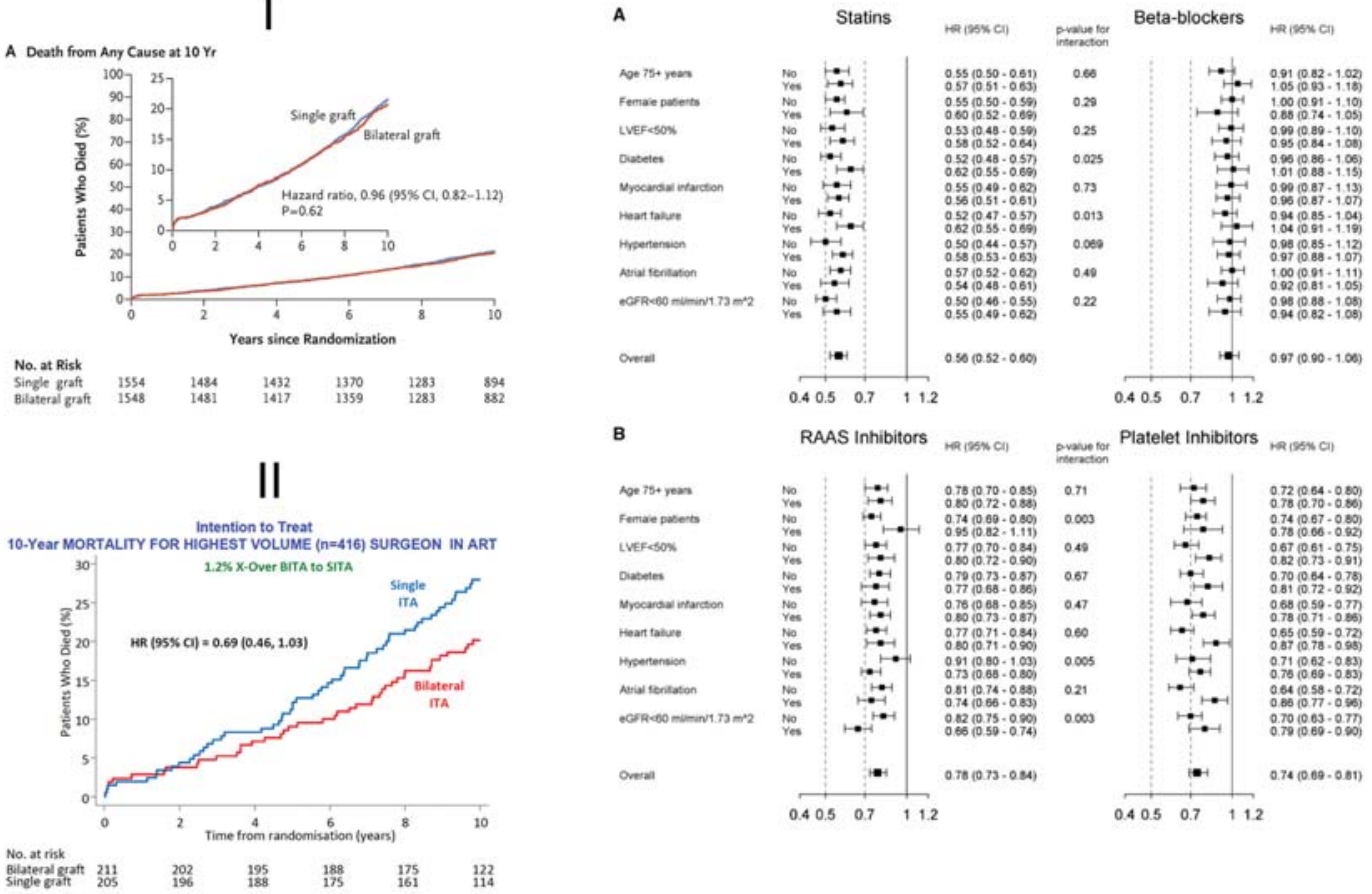

\section{preverese
premation
0.070}

Lefeson.

Dusetes

reart taver

Heat taber

Arical feritation

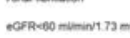

amat

B

$0.40 .5 \quad 0.7 \quad 11.2$

Ne $75+$ ven

Femae parento

Iverson

Disenter

mpocuras inst

meart touve

Arial tontention

omeat
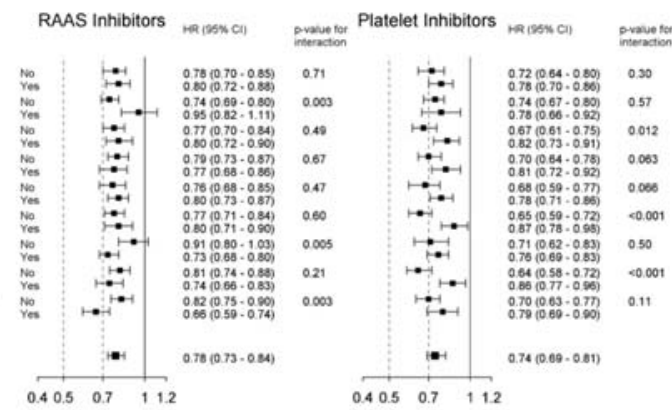

Fig. 2 Main findings of 2019 publications on the conduct of coronary bypass surgery. (A) Main illustration of the GRAFITTI trial, assessing the impact of using FFR assessment for bypass grafting. ${ }^{23}$ (Reproduced with permission.) (B) Long-term survival of the entire GOPCABE trial patient population (off-pump vs. on-pump in the elderly) compared the age-matched German population. ${ }^{27}$ (Reproduced with permission.) (C) (I) All-cause mortality of the ART trial comparing bilateral versus single internal thoracic artery grafting. ${ }^{31}$ (Reproduced with permission.) (II) All-cause mortality for patients with single or bilateral internal thoracic artery grafting of the ART trial surgeon who included the most patients and who had the lowest crossover rate. ${ }^{32}$ (Reproduced with permission.) (D) Mortality hazard ratios for different drug classes used in the treatment of patients having received coronary bypass grafting in Sweden (data from the SWEDEHEART registry). Statins had the largest impact on survival. ${ }^{34}$ (Reproduced with permission.) FFR, fractional flow reserve.

an impact of the conduct of surgery. ${ }^{31}$ Most importantly, the trial demonstrated that if the highest volume of surgeon's outcomes were assessed (he/she had the lowest crossover rate from double to single internal thoracic artery use and performed $95 \%$ of cases off-pump), there was a significant survival advantage for the use of bilateral thoracic arteries ( - Fig. 2C, II). ${ }^{32}$ These findings demonstrated again, what many other publications have suggested before, that individual sur- gical precision is a critical factor for optimal long-term outcome.

\section{The Role of Medical Therapy in CABG Patients}

The importance of medical therapy for patients having received coronary bypass grafting has already been stressed in the recently renewed European Society of Cardiology guidelines on coronary revascularization. In 2019, the TiCAB 
trial did not demonstrate an advantage of adding ticagrelor to aspirin in patients fresh after coronary bypass surgery. ${ }^{33}$

One of the most interesting observations, this year, came from the Swedeheart registry, where the investigators demonstrated a $40 \%$ risk reduction in mortality by using statins (and also using renin-angiotensin-aldosterone system inhibitors) postoperatively ( - Fig. 2D). ${ }^{34}$ Again, a treatment strategy reducing the risk of myocardial infarction is associated with a survival advantage.

The main findings of 2019 publications on surgical treatment for CAD are:

- Superiority of CABG over PCI appears to be due to surgical collateralization and infarct protection.

- The prognostic relevance of revascularization in chronic coronary syndromes is still questionable.

- Coronary CT has the potential to suffice for CABG planning.

- Fully arterial CABG plus optimal surgical competence appears to be associated with the best long-term survival.

- Medical therapy is important after CABG, specifically the use of statins.

\section{Aortic Valve Surgery}

\section{TAVI versus SAVR}

In 2019, the contest between transcatheter aortic valve implantation (TAVI) and surgical aortic valve replacement (SAVR) continued. Two randomized trials presented their primary outcome in patients with low operative risk (i.e., Society of Thoracic Surgery [STS] score $<3 \%$ ). The Evolut Low Risk trial randomized 1,400 patients to either conventional surgery or transfemoral TAVI using the Evolut R, the Evolut Pro, or the CoreValve prosthesis and demonstrated equal outcome of the primary end point of death or disabling stroke ( $\mathbf{- F i g . ~ 3 A )} .^{35}$ There was a trend toward less adverse events periprocedurally. However, the difference was not significant. The other trial was the PARTNER 3 study that randomized nearly 1,000 patients to either SAVR or TAVI using the transfemoral Sapien 3 prosthesis. ${ }^{36}$ The mean STS score was $1.9 \%$. In this trial, the combined end point of death, stroke, or rehospitalization at 12 months was superior for TAVI (-Fig. 3B). The difference was also visible in the single end points, although not significant for mortality.

A meta-analysis then summarized the data of all available prospective randomized trials of all risk categories. ${ }^{37}$ While mortality was never significantly different between TAVI and SAVR in the individual trials, the combined assessment presented significantly lower mortality with TAVI $(p=0.03)$. This advantage was exclusively caused by patients receiving transfemoral TAVI. In addition, TAVI patients presented with less periprocedural renal failure, atrial fibrillation but more need for pacemaker implantation, paravalvular leaks, and vascular complications. In addition, there was a trend toward more endocarditis in the TAVI population, although the incidence in general was low.

While it appears from these data, that TAVI is certainly not inferior (if not superior) to SAVR in the perioperative period, long-term follow-ups are still missing (for obvious reasons).
In 2019, the 5-year outcomes for PARTNER II were presented and an Italian registry demonstrated a propensity-matched analysis. While in PARTNER II, where the Sapien XT valve was randomized to classic surgery in patients with intermediate risk, the primary outcome of death disabling stroke was not significantly different at 5 years, a landmark analysis demonstrated that the curves crossed between 2 and 3 years and that surgery provided significantly improved outcome in the second half (-Fig. $\mathbf{3 C}$ ). ${ }^{38}$ The Italian registry analysis, where 650 risk-adjusted patient pairs out of 8,000 patients with either TAVI or SAVR were compared, also demonstrated a significant survival advantage for SAVR at 5 years (-Fig. 3D). ${ }^{39}$ Finally, a single-center propensity-matched comparison in low-risk patients (109 pairs, EuroSCORE II $<4 \%$ ) suggested similar outcomes between TAVI and SAVR at 1 year, but a remarkable (and significant) survival advantage for SAVR after 5 years. ${ }^{40}$ Thus, longer follow-up appears necessary.

While durability of tissue valves may be one explanation for this possible difference at 5 years, one summary of the available information ${ }^{41}$ and one outcome study of the NOTION trial illustrated that signs for structural valve deterioration were even lower in the TAVI population, although the rates of valve failure were low and the same in both groups. ${ }^{42}$ Thus, the differences in mortality observed in several studies $39,40,43,44$ may not be explained by differences in midterm durability.

Aortic stenosis is often accompanied by other cardiac pathologies. The presence of concomitant mitral stenosis was analyzed in 971 TAVI patients over an 8-year period in a single-center study. ${ }^{45}$ The authors found signs of mitral stenosis in 176 of almost 1,000 patients. They could demonstrate that the presence of mitral stenosis increased the rate of stroke and cardiovascular death depending on the severity of the stenosis.

Another issue related to adverse events, specifically in TAVI patients, is the occurrence of prosthetic valve thrombosis, which is occurring about four times as often as in classic surgery. ${ }^{46}$ In 2019, the GALILEO trial published its primary outcome, where aspirin plus rivaroxaban was compared with a double platelet inhibition strategy post-TAVI. The trial confirmed the high occurrence of valve thrombosis in the TAVI population and also demonstrated the efficacy of anticoagulation to prevent or treat this problem. However, the trial also demonstrated increased mortality in the group with aspirin plus rivaroxaban, creating a "catch-22 situation" for a not insignificant fraction of patients receiving TAVI. Taking these findings together, it underscores the need for individualized and joint decision making and comprehensive consenting of patients with severe aortic stenosis.

\section{Classic Aortic Valve Surgery}

The first prospective randomized evidence for the efficacy of SAVR in asymptomatic patients with severe aortic stenosis emerged in 2019. The RECOVERY trial $^{47}$ randomized 145 asymptomatic patients with flow velocities above $4.5 \mathrm{~m} / \mathrm{s}$ or mean pressure gradients above $50 \mathrm{~mm} \mathrm{Hg}$ randomized to early surgery to a conservative strategy until a guideline indication for valve replacement occurred. In the surgical 

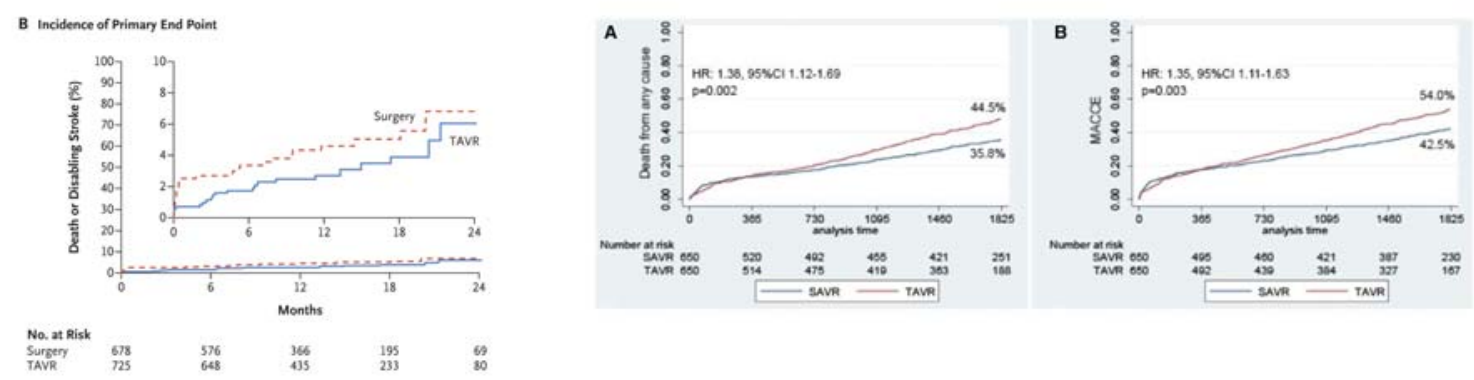

B
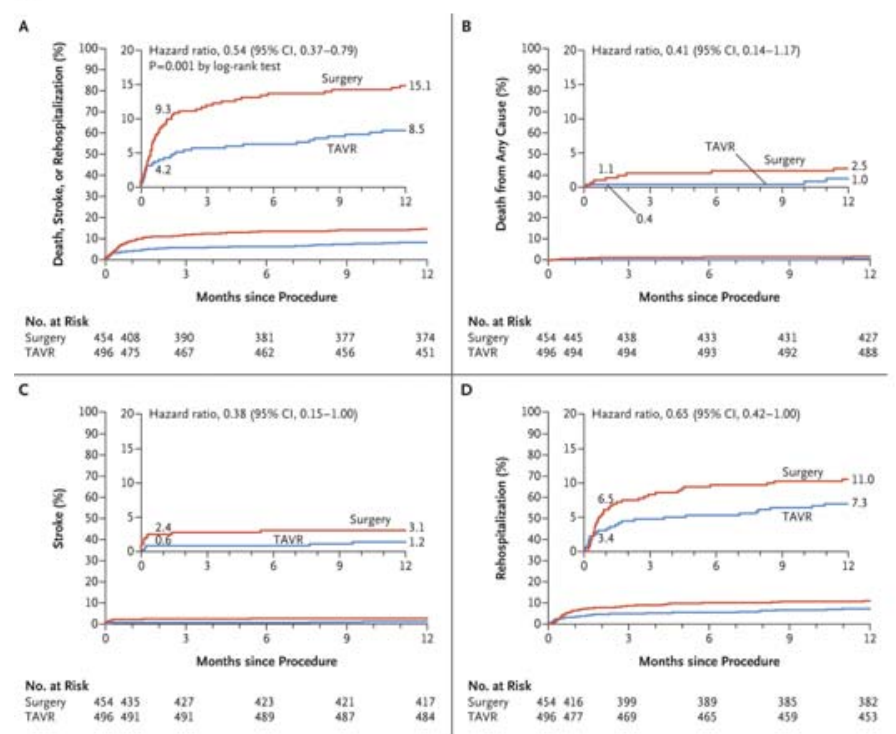

C

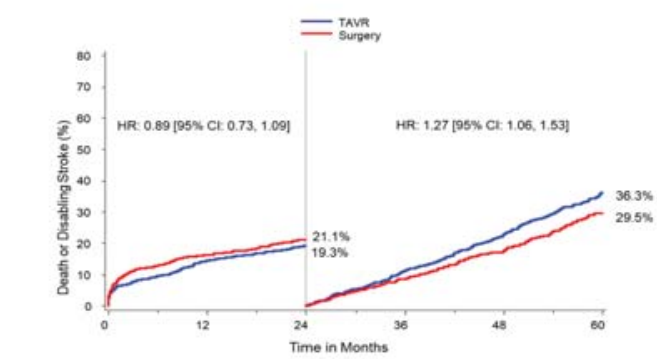

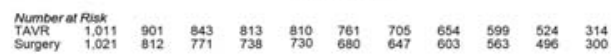

E

A Operative Mortality or Death from Cardiovascular Causes
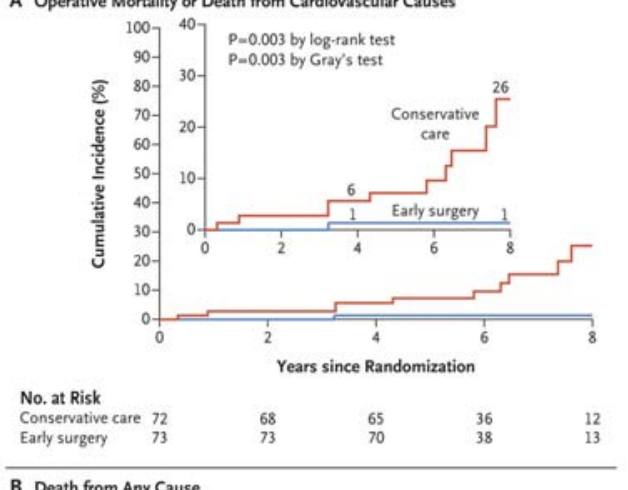

B Death from Any Cause

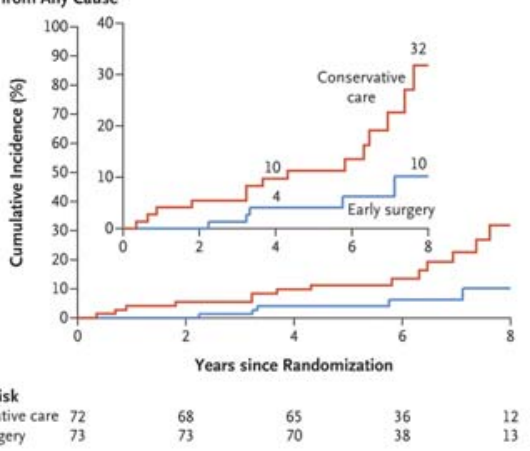

Fig. 3 Main findings of 2019 publications on aortic valve surgery. (A) Primary outcome of the Evolut Low Risk trial. ${ }^{35}$ (Reproduced with permission.) (B) Primary outcome of the PARTNER 3 trial. ${ }^{36}$ (Reproduced with permission.) (C) Landmark analysis of the first 2 and the following 3 years of the PARTNER II trial. ${ }^{38}$ (Reproduced with permission.) (D) Death from any cause (left panel) and MACE (right panel) of a propensity core matched analysis of an Italian registry comparing TAVI and SAVR at 5 years. ${ }^{39}$ (Reproduced with permission.) (E) Primary outcome (combined end point: A and all-cause death: B) of the RECOVERY trial comparing early SAVR in asymptomatic patients with aortic stenosis versus conservative (according to current guidelines) treatment. ${ }^{47}$ (Reproduced with permission.) MACE, major adverse cardiac events; SAVR, surgical aortic valve replacement; TAVI, transcatheter aortic valve implantation.

group, $95 \%$ of patients received aortic valve replacement within 2 months. During the 8-year follow-up, three quarters of patients in the conservative group required surgery for meeting guideline-conform indications. The primary end point consisted of operative mortality or cardiovascular death during follow-up. It was significantly higher in the conservative group, as was all-cause mortality (-Fig. 3E).

Another interesting analysis in this context is a singlecenter observational study of 614 patients above 75 years of age having received classic aortic valve replacement. ${ }^{48}$ The 
authors compared these surgical patients with 61,000 persons of the normal population (1-100 matched). The analysis demonstrated that those patients having survived surgery had normal life expectancy thereafter and that mortality was only higher in the year of surgery. These data support the efficacy of mechanical elimination of an aortic valve stenosis and the excellent long-term outcomes of classic aortic valve replacement.

With respect to valve durability, there were many publications in 2019 mainly focused on the gray zone in the guidelines (i.e., patients at age between 50 and 70 years). All these publications demonstrated that biological prostheses are not associated with a poorer survival compared with mechanical prostheses. ${ }^{49-54}$ They presented less bleeding and thrombotic events but required higher rates of reoperation. $^{50,51,54}$ These findings were also true for patients with end-stage renal failure. ${ }^{50,52,53}$

The main findings of 2019 publications on surgical treatment of aortic valve disease are:

- Transfemoral TAVI may be superior to surgical AVR in the periprocedural/perioperative period.

- This advantage appears to get lost over time and surgery may become superior at 5 years.

- In patients receiving classic SAVR, the selection of a biological prosthesis does not limit prognosis. This also seems to be true in patients with end-stage renal failure.

\section{Mitral and Tricuspid Valves Surgery}

\section{Mitral Valve}

The last year in mitral valve surgery was mainly characterized by discussions around the COAPT and the MITRA FR trials. ${ }^{55,56}$ The COAPT trial had demonstrated superior outcome for MitraClip versus medical therapy in patients with functional mitral regurgitation (MR) including a significant survival advantage, while MITRA FR did not find any differences between MitraClip and medical therapy even at 2 years. ${ }^{56}$ However, we ${ }^{57}$ and others ${ }^{58}$ have questioned plausibility of the COAPT results because of inconsistent echocardiographic measurements. The authors had not provided the regurgitant volume in their original publication in $2018 .^{59}$ We had suggested that based on the available data, it was impossible for these patients to generate a forward cardiac output because the expected regurgitant volume would be equal to total stroke volume. In 2019, the authors then presented values that fully support our concern (regurgitation volume: device group: $59.7 \pm 21.0 \mathrm{~mL}$ and control group: $59.9 \pm 23.5 \mathrm{~mL}$ ). ${ }^{55}$ They went on to suggest the concept of disproportionate MR as possible explanation, ${ }^{60}$ where the relationship of effective regurgitant orifice (ERO) and the regurgitant volume is not supposed to be proportionate any more (specifically in smaller ventricles). Although the idea of this disproportionate MR may be intriguing, the math still does not add up. If MR is disproportionate because there is more regurgitant volume than expected from the ERO, calculated cardiac outputs will become even more negative, which is not possible. If the MR is disproportionate because the regurgitant volume is lower than expected from the ERO, the MR may not be relevant anymore. Considering these plausibility problems for the echocardiographical quantification of functional MR, patient selection based on echocardiography (especially for those deriving the suggested prognostic effect) appears very difficult.

Harmel et al published a study addressing the surgical treatment of functional MR. ${ }^{61}$ The authors analyzed around 100 consecutive patients who either received an annuloplasty alone or an annuloplasty plus an additional subvalvular technique, anchoring the two papillary muscles independently to the implanted annuloplasty ring. The authors demonstrated superior outcome for the subvalvular group, where improved 5 -year survival was associated with less return of severe MR ( - Fig. 4A). Although the technique does not fully address the underlying pathology of FMR, ${ }^{62}$ it importantly demonstrates that a subvalvular technique, stabilizing the geometric dimension of a repair, results in better durability, which may be associated with a survival advantage. Thus, this study underscores that future trials on FMR still require a surgical arm.

While the earlier investigations addressed functional MR, Buzzatti et al compared 100 MitraClip-treated with 206 surgically treated patients with an age older than 75 years, an STS score of less than $8 \%$ and with structural MR as underlying pathology. The authors found a trend toward less periprocedural complications in the MitraClip group but a tremendous survival advantage for surgery after 5 years, with the curves diverging after 1 year ( $\mathbf{F i g . ~ 4 B )}{ }^{63}$ These results suggest that mitral valve repair remains the gold standard for operable patients even at older age.

A meta-analysis of 12 studies having included patients with structural MR compared outcomes for mitral valve repair with replacement. ${ }^{64}$ In almost 3,000 patients, the authors demonstrated a significant survival advantage for mitral valve repair, which was again independent of age (-Fig. 4C). In case mitral valve replacement is required, a risk-adjusted analysis on 138 patients with biological mitral valve prostheses then demonstrated that patients who received $\beta$ blocker therapy showed higher freedom from structural valve deterioration ( - Fig. 4D). ${ }^{65}$ If mitral valve surgery is indicated in the presence of previous cardiac surgery, the valve can be approached through a minirightsided thoracotomy. This type of surgery performed mainly on the fibrillating heart was compared with classic redo sternotomy by Patel et al. ${ }^{66}$ Propensity matching of reoperative mitral valve cases ( 90 patient pairs out of more than 400) demonstrated no difference in survival, but faster mobilization, earlier discharge and a trend toward lower operating times in the minimally invasive group.

\section{Tricuspid Valve}

A comparison of repair and replacement was also published for the tricuspid valve. The Mayo Clinic analyzed their database between 1993 and 2013 and presented a riskadjusted comparison of 1,735 patients with tricuspid repair with 806 patients with tricuspid replacement. ${ }^{67}$ The authors demonstrated a significantly better survival after 15 years in the repair group and suggest performing repair whenever possible (-Fig. 4E). 
A
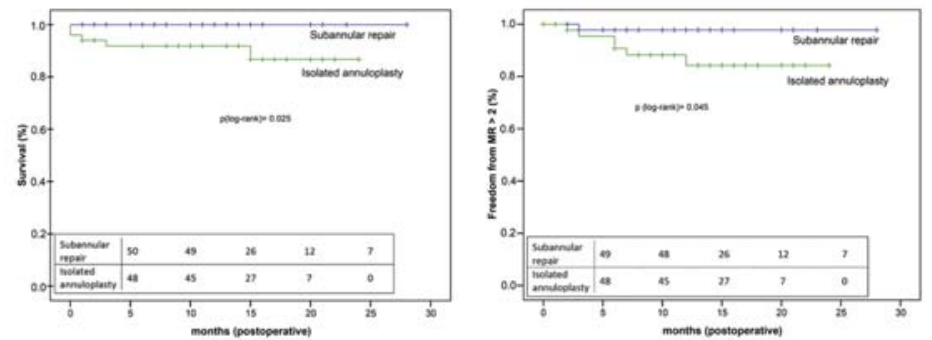

B

\section{I}

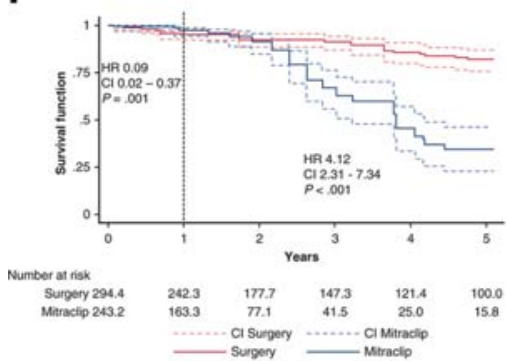

II

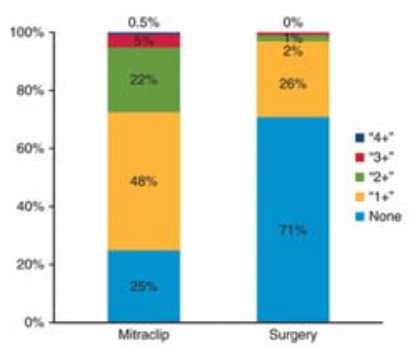

D

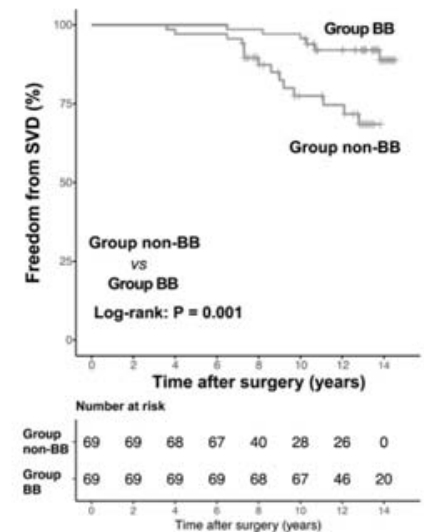

C

(B)

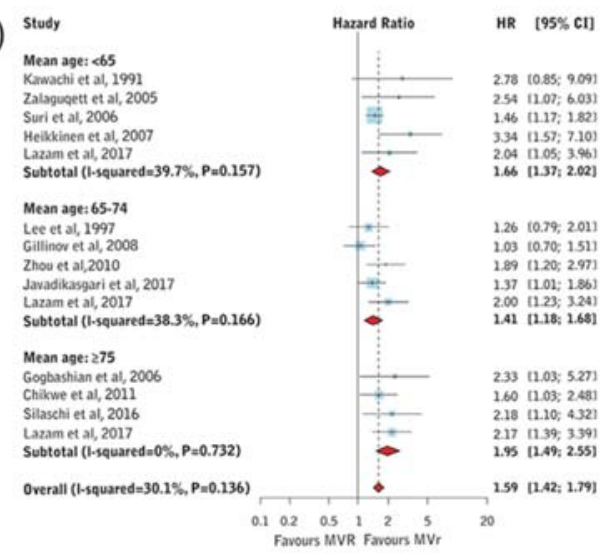

E

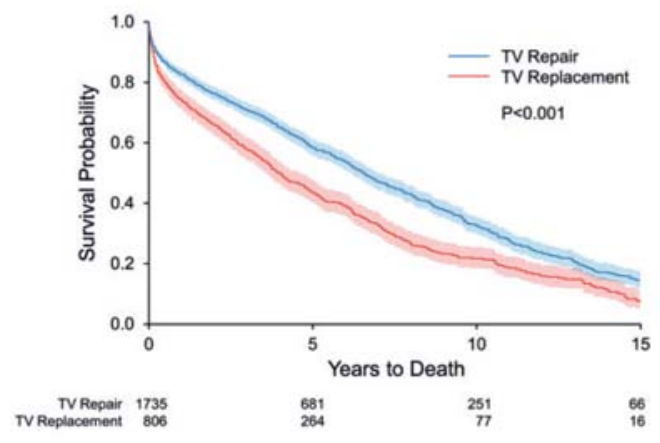

Fig. 4 Main findings of 2019 publications on mitral and tricuspid valves surgery. (A) Survival (left panel) and freedom from severe mitral regurgitation in patients with functional mitral regurgitation either received annuloplasty only or annuloplasty plus a subvalvular technique. ${ }^{61}$ (Reproduced with permission.) (B) Survival (I) and posttreatment prevalence of mitral regurgitation (II) in patients who received MitraClip or surgical treatment for structural mitral regurgitation. ${ }^{63}$ (Reproduced with permission.) (C) Meta-analysis of trials comparing mitral valve replacement (MVR) with mitral valve repair (MVr) in patients with structural MR. ${ }^{64}$ (Reproduced with permission.) (D) Freedom from structural valve deterioration (SVD) after bioprosthetic valve replacement in patients who did (BB) or did not (non-BB) receive $\beta$ blocker therapy. ${ }^{65}$ (Reproduced with permission.) (E) Long-term survival in risk-adjusted patients who received either tricuspid valve repair or replacement for tricuspid regurgitation. ${ }^{67}$ (Reproduced with permission.) 
Another publication confirmed previous studies and guideline recommendations, by demonstrating that adding tricuspid repair to an otherwise indicated cardiac operation does not increase operative risk and leads to improvement in right ventricular function during follow-up. ${ }^{68}$ Their analysis was performed on 300 risk-adjusted patient pairs, where tricuspid regurgitation was mild to moderate and there was evidence for annulus dilatation.

A Texan publication then demonstrated their experience with 95 isolated tricuspid valve operations out of 685 operations addressing the tricuspid valve between 2007 and 2017. In the isolated cohort, the authors found a mortality of 3.2\%, without having lost a single patient in the past 6 years. The authors suggest that tricuspid valve surgery is safe today and that these outcomes should serve as benchmark for interventional procedures. ${ }^{69}$

A provocative analysis was then published from the Massachusetts General Hospital, questioning a survival advantage possibly provided by tricuspid valve surgery. ${ }^{70}$ The authors performed a risk-adjusted comparison of 171 patients having received tricuspid surgery with more than 3,000 patients treated conservatively. While the direct comparison showed superiority of surgery, considering an immortal time bias, the difference was no longer present. The authors also did not find a difference between repair and replacement. While this information was prominently published, the immortal time bias comparison contains only 19 surgical patients. In addition, the authors write $\sim 85 \%$ repairs but show $85 \%$ replacement. Finally, the findings are in stark contrast with a previous publication from the Brigham and Women's Hospital suggesting a survival impact of tricuspid surgery.

The main findings of 2019 for mitral and tricuspid valves surgery are:

- The debate on MitraClip efficacy continues, with COAPT echodata still being inconsistent.

- Surgical treatment of functional MR may still afford a survival advantage if the proper surgical technique is applied.

- Surgery appears superior to MitraClip in structural MR.

- Repair of the mitral or the tricuspid valves may afford a survival advantage over replacement.

- $\beta$ blocker therapy may improve durability of biological prosthesis in the mitral position.

\section{Surgery of the Aorta}

Three publications in 2019 addressed generally important information on the treatment of acute type A dissections. First, a Japanese registry analysis on more than 10,000 patients demonstrated that surgical treatment of type $A$ dissections has improved over the years despite the fact that patients have become older. They also demonstrate that patients receiving replacement of the ascending aorta plus partial arch only tended to have better outcomes than those with full arch replacement. However, this difference became smaller over time indicating increased competence and handling of these difficult surgical cases. ${ }^{71}$
An analysis from the University of Stanford assessed their experience of 345 patients with type A dissections focusing on preexisting neurological injury. ${ }^{72}$ The authors found that preexisting neurological injury increased perioperative risk, but the duration of symptoms before surgery did not influence perioperative mortality or potential neurological recovery. Thus, they suggest operating on patients irrespective of preexisting neurological injuries.

Another complication of type A dissections is the development of mesenteric ischemia. Yang et al demonstrated their experience on 602 patients between 1996 and 2017 from the University of Michigan in Ann Arbor. ${ }^{73}$ Mesenteric ischemia was present in 82 patients. The authors demonstrate that interventional fenestration or stent implantation aimed at relieving bowel ischemia before the thoracic aorta is addressed results in excellent outcomes. All patients were ischemia was successfully relieved could be operated on the thoracic aorta at normal risk.

\section{Surgery for Terminal Heart Failure}

Important new information was published in 2019 in the field of terminal heart failure. The MOMENTUM 3 trial, in which the centrifugal pump HeartMate 3 was compared with the axial-flow pump HeartMate II published its final report. ${ }^{74}$ The authors demonstrated a significant reduction in strokes, pump thromboses, and gastrointestinal bleedings with the new HeartMate 3 (-Fig. 5A).

Gastrointestinal bleedings in the context of continuous flow ventricular assist devices are considered to be caused by arteriovenous malformations. Converse et al analyzed a series of 111 patients for gastrointestinal bleedings and demonstrated a $60 \%$ reduction in bleeding risk when ACE inhibitors were part of the patients' medication. The authors suggest that the inhibition of an angiotensin receptor-mediated mechanism reduces the induction of arteriovenous malformations (- Fig. 5B). ${ }^{75}$

A consensus paper of the European Association of CardioThoracic Surgery then summarized current recommendations for ventricular assist device use. It documents that long-term mechanical support is an established therapy for terminal heart failure. ${ }^{76}$

The use of intramyocardial injections of mesenchymal stem cells has been suggested to improve contractile recovery during left ventricular support. The efficacy of this treatment was tested by the American surgical research network, Cardiothoracic Surgical Trials Network in a prospective randomized trial including 159 patients. ${ }^{77}$ Despite great expectations, injection of stem cells into mechanically supported failing hearts did not generate a detectable effect within the 6 months observation period.

The use of mechanical support increased in recent years because suitable donor organ is often not readily available (i.e., bridge to transplantation due to organ shortage). An analysis of the United Network for Organ Sharing analyzed the impact of previous mechanical support on heart transplantation outcomes. On more than 5,000 patients who received a heart transplantation between 2008 and 2015, a 
A

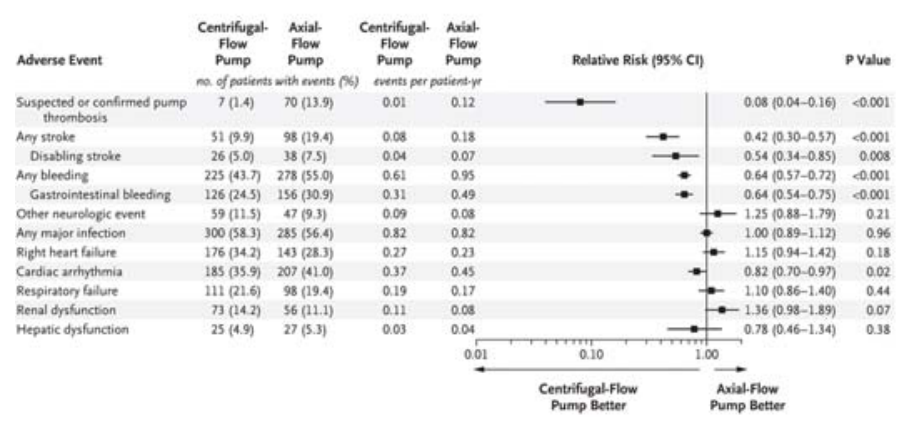

C

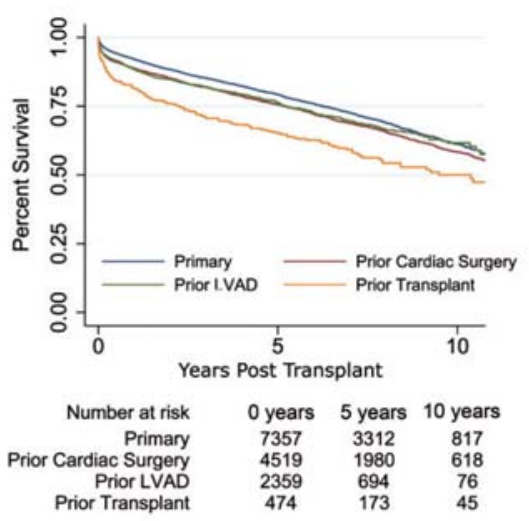

B

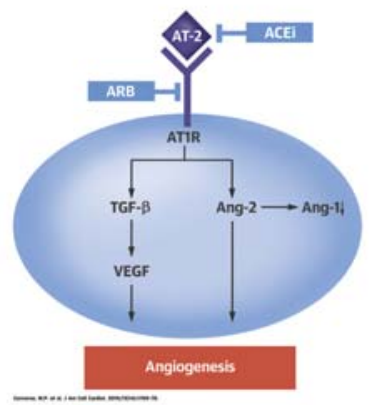

D

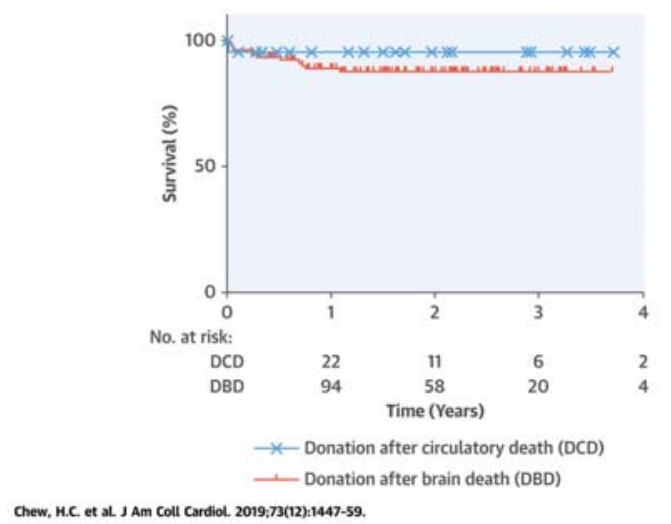

Fig. 5 Main findings of 2019 publications on surgery for terminal heart failure. (A) Forest plot for main outcomes of the MOMENTUM 3 trial comparing the HeartMate II to the HeartMate 3 device. ${ }^{74}$ (Reproduced with permission.) (B) Suggested angiotensin receptor-mediated mechanism for gastrointestinal neoangiogenesis associated with nonpulsatile ventricular assist device therapy. ${ }^{75}$ (Reproduced with permission.) (C) Survival in patients having undergone heart transplantation as primary or redo (separated in to previous heart, previous LVAD, or previous heart transplantation) surgery. ${ }^{79}$ (Reproduced with permission.) (D) Survival after heart transplantation in patients having received organs from brain-dead or circulatory-death donors. ${ }^{81}$ (Reproduced with permission.) LVAD, left ventricular assist device.

risk-adjusted comparison of patients transplanted from assist devices with patients primarily transplanted was performed. The authors identified the presence of a left ventricular assist device (LVAD) as significant risk factor. Long-term survival was worse in patients with previous mechanical support. ${ }^{78} \mathrm{~A}$ second analysis also analyzed the same database, but between 2005 and 2017. They identified more than 14,000 patients with heart transplantations and identified not only the presence of an LVAD but also previous cardiac surgery as risk factors. Patients who had previous heart transplantations had the worst survival (-Fig. 5C). ${ }^{79}$ The authors suggest to critically consider the presence of an LVAD in the context of donor heart allocation.

Other options against organ shortage are directed at increasing the donor pool. An analysis from Boston, where 44 lungs or hearts of hepatitis $C$ positive donors were transplanted combined with a 4-week antiviral treatment strategy, demonstrated normal long-term results without hepatitis $\mathrm{C}$ infection of the recipient. ${ }^{80}$

The current strategy in heart transplantation is the use of brain-dead (i.e., heart beating) donors. With the advent of the organ care system, the use of hearts from circulatory-death donors became possible. Here, the heart of a circulatory- death donor is implanted into the in vitro perfusion system and recovery of function is assessed. Hearts with adequate recovery may be used for transplantation. In 2019, an Australian center presented their experience with this technique. ${ }^{81}$ The center explanted 33 organs for clinical use and it was possible to transplant 23 of those hearts successfully. With the exception of one early death, all patients having received those organs survived the first 4 years ( $\mathbf{- F i g . 5 D )}$. Given the successful experience of others, ${ }^{82}$ this technique is an attractive perspective in heart transplantation

\section{Conflict of Interest}

None declared.

\section{Acknowledgment}

We would like to thank Benjamin May for expert technical assistance in the preparation of the manuscript.

\section{References}

1 Head SJ, Milojevic M, Daemen J, et al. Mortality after coronary artery bypass grafting versus percutaneous coronary intervention with stenting for coronary artery disease: a pooled analysis of individual patient data. Lancet 2018;391(10124):939-948 
2 Neumann FJ, Sousa-Uva M, Ahlsson A, et al; ESC Scientific Document Group. 2018 ESC/EACTS guidelines on myocardial revascularization. Eur Heart J 2019;40(02):87-165

3 Doenst T, Haverich A, Serruys P, et al. PCI and CABG for treating stable coronary artery disease: JACC review topic of the week. J Am Coll Cardiol 2019;73(08):964-976

4 Falk E, Shah PK, Fuster V. Coronary plaque disruption. Circulation 1995;92(03):657-671

5 Stergiopoulos K, Boden WE, Hartigan P, et al. Percutaneous coronary intervention outcomes in patients with stable obstructive coronary artery disease and myocardial ischemia: a collaborative meta-analysis of contemporary randomized clinical trials. JAMA Intern Med 2014;174(02):232-240

6 Jeon C, Candia SC, Wang JC, et al. Relative spatial distributions of coronary artery bypass graft insertion and acute thrombosis: a model for protection from acute myocardial infarction. Am Heart J 2010;160(01):195-201

7 Lee PH, Park H, Lee JS, Lee SW, Lee CW. Meta-analysis comparing the risk of myocardial infarction following coronary artery bypass grafting versus percutaneous coronary intervention in patients with multivessel or left main coronary artery disease. Am J Cardiol 2019;124(06):842-850

8 Farkouh ME, Domanski M, Dangas GD, et al; FREEDOM Follow-On Study Investigators. Long-term survival following multivessel revascularization in patients with diabetes: the FREEDOM follow-on study. J Am Coll Cardiol 2019;73(06):629-638

9 Ebrahim MEBM, Dignan R, Femia G, et al. Late clinical outcomes of unselected patients with diabetic mellitus and multi-vessel coronary artery disease. Int J Cardiol 2019;296:21-25

10 Sá MPBO, Perazzo AM, Saragiotto FAS, et al. Coronary artery bypass graft surgery improves survival without increasing the risk of stroke in patients with ischemic heart failure in comparison to percutaneous coronary intervention: a meta-analysis with 54,173 patients. Braz J Cardiovasc Surg 2019;34(04):396-405

11 Ram E, Sternik L, Klempfner R, et al. Outcomes of different revascularization strategies among patients presenting with acute coronary syndromes without ST elevation. J Thorac Cardiovasc Surg 2019; *.*:S0022-5223(19)32010-0

12 Freitas P, Madeira M, Raposo L, et al. Coronary artery bypass grafting versus percutaneous coronary intervention in patients with non-ST-elevation myocardial infarction and left main or multivessel coronary disease. Am J Cardiol 2019;123(05): 717-724

13 Thuijs DJFM, Kappetein AP, Serruys PW, et al; SYNTAX Extended Survival Investigators. Percutaneous coronary intervention versus coronary artery bypass grafting in patients with threevessel or left main coronary artery disease: 10-year follow-up of the multicentre randomised controlled SYNTAX trial. Lancet 2019;394(10206):1325-1334

14 Gaipov A, Molnar MZ, Potukuchi PK, et al. Predialysis coronary revascularization and postdialysis mortality. J Thorac Cardiovasc Surg 2019;157(03):976-983.e7

15 Stone GW, Kappetein AP, Sabik JF, et al; EXCEL Trial Investigators. Five-year outcomes after PCI or CABG for left main coronary disease. N Engl J Med 2019;381(19):1820-1830

16 Ruel M, Falk V, Farkouh ME, et al. Myocardial revascularization trials. Circulation 2018;138(25):2943-2951

17 Holm NR, Makikallio T, Lindsay MM, et al. Percutaneous coronary angioplasty versus coronary artery bypass grafting in the treatment of unprotected left main stenosis: updated 5-year outcomes from the randomised, non-inferiority NOBLE trial. Lancet 2020; 395(10219):191-199

18 Boden WE, O'Rourke RA, Teo KK, et al; COURAGE Trial Research Group. Optimal medical therapy with or without PCI for stable coronary disease. N Engl J Med 2007;356(15):1503-1516

19 Panza JA, Ellis AM, Al-Khalidi HR, et al. Myocardial viability and long-term outcomes in ischemic cardiomyopathy. N Engl J Med 2019;381(08):739-748
20 Garzillo CL, Hueb W, Gersh B, et al. Association between stress testing-induced myocardial ischemia and clinical events in patients with multivessel coronary artery disease. JAMA Intern Med 2019;179(10):1345-1351

21 Collet C, Onuma Y, Andreini D, et al. Coronary computed tomography angiography for heart team decision-making in multivessel coronary artery disease. Eur Heart J 2018;39(41):3689-3698

22 Sonck J, Miyazaki Y, Collet C, et al. Feasibility of planning coronary artery bypass grafting based only on coronary computed tomography angiography and CT-derived fractional flow reserve: a pilot survey of the surgeons involved in the randomized SYNTAX III Revolution trial. Interact Cardiovasc Thorac Surg 2019;•••:ivz046

23 Toth GG, De Bruyne B, Kala P, et al. Graft patency after FFR-guided versus angiography-guided coronary artery bypass grafting: the GRAFFITI trial. EuroIntervention 2019;15(11):e999-e1005

24 Glineur D, Grau JB, Etienne PY, et al. Impact of preoperative fractional flow reserve on arterial bypass graft anastomotic function: the IMPAG trial. Eur Heart J 2019;40(29):2421-2428

25 Benedetto U, Puskas J, Kappetein AP, et al. Off-pump versus onpump bypass surgery for left main coronary artery disease. J Am Coll Cardiol 2019;74(06):729-740

26 Rufa MI, Ursulescu A, Nagib R, et al. Off-pump versus on-pump redo coronary artery bypass grafting: a propensity score analysis of long-term follow-up. J Thorac Cardiovasc Surg 2019; •.*:S00225223(19)30971-7

27 Diegeler A, Börgermann J, Kappert U, et al. Five-year outcome after off-pump or on-pump coronary artery bypass grafting in elderly patients. Circulation 2019;139(16):1865-1871

28 Chikwe J, Sun E, Hannan EL, et al. Outcomes of second arterial conduits in patients undergoing multivessel coronary artery bypass graft surgery. J Am Coll Cardiol 2019;74(18):2238-2248

29 Ruttmann E, Dietl M, Feuchtner GM, et al; RADIAL Investigators. Long-term clinical outcome and graft patency of radial artery and saphenous vein grafts in multiple arterial revascularization. J Thorac Cardiovasc Surg 2019;158(02):442-450

30 Samadashvili Z, Sundt TM III, Wechsler A, et al. Multiple versus single arterial coronary bypass graft surgery for multivessel disease. J Am Coll Cardiol 2019;74(10):1275-1285

31 Taggart DP, Benedetto U, Gerry S, et al; Arterial Revascularization Trial Investigators. Bilateral versus single internal-thoracic-artery grafts at 10 years. N Engl J Med 2019;380(05):437-446

32 Taggart DP. Randomized comparison of single versus bilateral internal thoracic artery grafts in 3102 CABG patients: major cardiovascular outcomes at ten years of follow up. Paper presented at the European Society of Cardiology; Munich, Germany; 2018

33 Schunkert H, Boening A, von Scheidt M, et al. Randomized trial of ticagrelor vs. aspirin in patients after coronary artery bypass grafting: the TiCAB trial. Eur Heart J 2019;40(29):2432-2440

34 Bjorklund E, Nielsen SJ, Hansson EC, et al. Secondary prevention medications after coronary artery bypass grafting and long-term survival: a population-based longitudinal study from the SWEDEHEART registry. Eur Heart J 2020;41(17):1653-1661

35 Popma JJ, Deeb GM, Yakubov SJ, et al; Evolut Low Risk Trial Investigators. Transcatheter aortic-valve replacement with a self-expanding valve in low-risk patients. N Engl J Med 2019; 380(18):1706-1715

36 Mack MJ, Leon MB, Thourani VH, et al; PARTNER 3 Investigators. Transcatheter aortic-valve replacement with a balloon-expandable valve in low-risk patients. N Engl J Med 2019;380(18): $1695-1705$

37 Siontis GCM, Overtchouk P, Cahill TJ, et al. Transcatheter aortic valve implantation vs. surgical aortic valve replacement for treatment of symptomatic severe aortic stenosis: an updated meta-analysis. Eur Heart J 2019;40(38):3143-3153

38 Makkar RR, Thourani VH, Mack MJ, et al; PARTNER 2 Investigators. Five-year outcomes of transcatheter or surgical aortic-valve replacement. N Engl J Med 2020;382(09):799-809 
39 Barbanti M, Tamburino C, D'Errigo P, et al; OBSERVANT Research Group. Five-year outcomes of transfemoral transcatheter aortic valve replacement or surgical aortic valve replacement in a real world population. Circ Cardiovasc Interv 2019;12(07):e007825

40 Schaefer A, Schofer N, Goßling A, et al. Transcatheter aortic valve implantation versus surgical aortic valve replacement in low-risk patients: a propensity score-matched analysis. Eur J Cardiothorac Surg 2019;56(06):1131-1139

41 Capodanno D, Søndergaard L, Tamburino C. Durability of transcatheter bioprosthetic aortic valves: the story so far. EuroIntervention 2019;15(10):846-849

42 Sondergaard L, Costa G. Transcatheter aortic valve replacement in patients with aortic stenosis and low surgical risk. J Am Coll Cardiol 2019;74(12):1541-1542

43 Armoiry X, Obadia JF, Pascal L, Polazzi S, Duclos A. Comparison of transcatheter versus surgical aortic valve implantation in highrisk patients: a nationwide study in France. J Thorac Cardiovasc Surg 2018;156(03):1017-1025.e4

44 Thourani VH. Five-year Outcomes from the PARTNER 2A Trial: Transcatheter vs. Surgical Aortic Valve Replacement in Intermediate-Risk Patients. Paper presented at the EACTS; Lisbon, Portugal; 2019

45 Asami M, Windecker S, Praz F, et al. Transcatheter aortic valve replacement in patients with concomitant mitral stenosis. Eur Heart J 2019;40(17):1342-1351

46 Makkar RR, Fontana G, Jilaihawi H, et al. Possible subclinical leaflet thrombosis in bioprosthetic aortic valves. N Engl J Med 2015;373(21):2015-2024

47 Kang DH, Park SJ, Lee SA, et al. Early surgery or conservative care for asymptomatic aortic stenosis. N Engl J Med 2020;382(02): $111-119$

48 Hernandez-Vaquero D, Diaz R, Alperi A, et al. Life expectancy of patients undergoing surgical aortic valve replacement compared with that of the general population. Interact Cardiovasc Thorac Surg 2020;30(03):394-399

49 Diaz R, Hernandez-Vaquero D, Alvarez-Cabo R, et al. Long-term outcomes of mechanical versus biological aortic valve prosthesis: systematic review and meta-analysis. J Thorac Cardiovasc Surg 2019;158(03):706-714.e18

50 Ikeno Y, Mukohara N, Fukumura Y, et al. Outcomes of valve replacement with mechanical prosthesis versus bioprosthesis in dialysis patients: a 16-year multicenter experience. J Thorac Cardiovasc Surg 2019;158(01):48-56.e4

51 Iribarne A, Leavitt BJ, Robich MP, et al; Northern New England Cardiovascular Disease Study Group. Tissue versus mechanical aortic valve replacement in younger patients: a multicenter analysis. J Thorac Cardiovasc Surg 2019;158(06):1529-1538.e2

52 Manghelli JL, Carter DI, Khiabani AJ, et al. A 20-year multicenter analysis of dialysis-dependent patients who had aortic or mitral valve replacement: implications for valve selection. J Thorac Cardiovasc Surg 2019;158(03):805-813.e2

53 Nakatsu T, Minakata K, Tanaka S, Minatoya K; PROGRESS-Kyoto Investigators. Intermediate-term outcomes of aortic valve replacement with bioprosthetic or mechanical valves in patients on hemodialysis. J Thorac Cardiovasc Surg 2019;157(06):2177-2186. e3

54 Rodríguez-Caulo EA, Macías D, Adsuar A, et al. Biological or mechanical prostheses for isolated aortic valve replacement in patients aged 50-65 years: the ANDALVALVE study. Eur J Cardiothorac Surg 2019;55(06):1160-1167

55 Asch FM, Grayburn PA, Siegel RJ, et al; COAPT Investigators. Echocardiographic outcomes after transcatheter leaflet approximation in patients with secondary mitral regurgitation: the COAPT trial. J Am Coll Cardiol 2019;74(24):2969-2979

56 Iung B, Armoiry X, Vahanian A, et al; MITRA-FR Investigators. Percutaneous repair or medical treatment for secondary mitral regurgitation: outcomes at 2 years. Eur J Heart Fail 2019;21(12): 1619-1627
57 Doenst T, Bargenda S, Kirov H, et al. Cardiac surgery 2018 reviewed. Clin Res Cardiol 2019;108(09):974-989

58 Crestanello JA, Oh JK, Schaff HV. Transcatheter mitral-valve repair in patients with heart failure. N Engl J Med 2019;380(20):1978

59 Stone GW, Lindenfeld J, Abraham WT, et al; COAPT Investigators. Transcatheter mitral-valve repair in patients with heart failure. $\mathrm{N}$ Engl J Med 2018;379(24):2307-2318

60 Grayburn PA, Sannino A, Packer M. Proportionate and disproportionate functional mitral regurgitation: a new conceptual framework that reconciles the results of the MITRA-FR and COAPT trials. JACC Cardiovasc Imaging 2019;12(02):353-362

61 Harmel E, Pausch J, Gross T, et al. Standardized subannular repair improves outcomes in type IIIb functional mitral regurgitation. Ann Thorac Surg 2019;108(06):1783-1792

62 Bothe W, Doenst T. Ring-Noose-String technique allows adjustable papillary muscle repositioning during minimally invasive mitral valve repair in patients with functional/ischemic mitral regurgitation. Thorac Cardiovasc Surg 2016;64(05):447-449

63 Buzzatti N, Van Hemelrijck M, Denti P, et al. Transcatheter or surgical repair for degenerative mitral regurgitation in elderly patients: a propensity-weighted analysis. J Thorac Cardiovasc Surg 2019;158(01):86-94.e1

64 Jung JC, Jang MJ, Hwang HY. Meta-analysis comparing mitral alve repair versus replacement for degenerative mitral regurgitation across all ages. Am J Cardiol 2019;123(03):446-453

65 Ma W, Tan Y, Shi Q Xu Z. Continuous beta-blocker therapy delays structural deterioration after bioprosthetic mitral valve replacement. Thorac Cardiovasc Surg 2019;67(07):554-556

66 Patel NC, Hemli JM, Seetharam K, et al. Reoperative mitral valve surgery via sternotomy or right thoracotomy: a propensitymatched analysis. J Card Surg 2019;34(10):976-982

67 Saran N, Dearani JA, Said SM, et al. Long-term outcomes of patients undergoing tricuspid valve surgery. Eur J Cardiothorac Surg 2019;56(05):950-958

68 Pingpoh C, Nuss S, Kueri S, et al. Adding tricuspid repair to standard open heart surgery does not increase risk but improves right ventricular function. Interact Cardiovasc Thorac Surg 2019; 29(03):416-421

69 Hamandi M, Smith RL, Ryan WH, et al. Outcomes of isolated tricuspid valve surgery have improved in the modern era. Ann Thorac Surg 2019;108(01):11-15

70 Axtell AL, Bhambhani V, Moonsamy P, et al. Surgery does not improve survival in patients with isolated severe tricuspid regurgitation. J Am Coll Cardiol 2019;74(06):715-725

71 Abe T, Yamamoto H, Miyata H, et al. Patient trends and outcomes of surgery for type A acute aortic dissection in Japan: an analysis of more than 10000 patients from the Japan Cardiovascular Surgery Database. Eur J Cardiothorac Surg 2020;57(04):660-667

72 Chiu P, Rotto TJ, Goldstone AB, Whisenant JB, Woo YJ, Fischbein MP. Time-to-operation does not predict outcome in acute type A aortic dissection complicated by neurologic injury at presentation. J Thorac Cardiovasc Surg 2019;158(03):665-672

73 Yang B, Norton EL, Rosati CM, et al. Managing patients with acute type A aortic dissection and mesenteric malperfusion syndrome: a 20-year experience. J Thorac Cardiovasc Surg 2019;158(03): 675-687.e4

74 Mehra MR, Uriel N, Naka Y, et al; MOMENTUM 3 Investigators. A fully magnetically levitated left ventricular assist device - final report. N Engl J Med 2019;380(17):1618-1627

75 Converse MP, Sobhanian M, Taber DJ, Houston BA, Meadows HB, Uber WE. Effect of angiotensin II inhibitors on gastrointestinal bleeding in patients with left ventricular assist devices. J Am Coll Cardiol 2019;73(14):1769-1778

76 Potapov EV, Antonides C, Crespo-Leiro MG, et al. 2019 EACTS Expert Consensus on long-term mechanical circulatory support. Eur J Cardiothorac Surg 2019;56(02):230-270

77 Yau TM, Pagani FD, Mancini DM, et al; Cardiothoracic Surgical Trials Network. Intramyocardial injection of mesenchymal precursor cells 
and successful temporary weaning from left ventricular assist device support in patients with advanced heart failure: a randomized clinical trial. JAMA 2019;321(12):1176-1186

78 Truby LK, Farr MA, Garan AR, et al. Impact of bridge to transplantation with continuous-flow left ventricular assist devices on posttransplantation mortality. Circulation 2019;140(06):459-469

79 Axtell AL, Fiedler AG, Lewis G, et al. Reoperative sternotomy is associated with increased early mortality after cardiac transplantation. Eur J Cardiothorac Surg 2019;55(06):1136-1143
80 Woolley AE, Singh SK, Goldberg HJ, et al; DONATE HCV Trial Team. Heart and lung transplants from HCV-infected donors to uninfected recipients. N Engl J Med 2019;380(17):1606-1617

81 Chew HC, Iyer A, Connellan M, et al. Outcomes of donation after circulatory death heart transplantation in Australia. J Am Coll Cardiol 2019;73(12):1447-1459

82 Messer S, Page A, Axell R, et al. Outcome after heart transplantation from donation after circulatory-determined death donors. J Heart Lung Transplant 2017;36(12):1311-1318 